\title{
Clinical value of monitoring eosinophil activity in asthma
}

\author{
D Y Koller, Y Herouy, M Götz, E Hagel, R Urbanek, I Eichler
}

\begin{abstract}
To evaluate the use of eosinophil cationic protein (ECP) in monitoring disease activity in childhood asthma, serum ECP in 175 asthmatic children was assessed. Forty five patients with cystic fibrosis, 23 with lower respiratory tract infections (LRTI), and 87 healthy children were used as controls.

Serum ECP concentrations $(34 \cdot 3 \mu \mathrm{g} / 1$ $v 9.8 \mu g / 1)$ were significantly higher in children with bronchial asthma than in healthy control subjects. In symptomatic patients with asthma serum ECP concentrations were increased compared with those from asymptomatic patients $(40 \cdot 2$ $\mu \mathrm{g} / 1 v 14.4 \mu \mathrm{g} / 1)$, irrespective of treatment modalities (that is steroids, $\beta_{2}$ agonists, or sodium cromoglycate). Moreover, atopy and infection appeared to be factors enhancing eosinophil activity in bronchial asthma as measured by serum ECP (58.4 $\mu \mathrm{g} / \mathrm{l} v 36.8 \mu \mathrm{g} / \mathrm{l}$ and $68.8 \mu \mathrm{g} / \mathrm{l} v 42.2 \mu \mathrm{g} / \mathrm{l}$, respectively). In a longitudinal trial, antiasthmatic treatment modalities (that is steroids) reduced serum ECP within four weeks $(42 \cdot 2 \mu g / 1 v 19 \cdot 0 \mu g / 1)$.

In conclusion, the data indicate that (1) eosinophils also play a central part in childhood asthma; (2) serum concentrations of ECP in children with bronchial asthma are related to the disease severity and may thus be used for monitoring inflammation in childhood asthma; (3) eosinophil activity appears to be enhanced by atopy and infection; and (4) longitudinal measurements of serum ECP concentrations may be useful for optimising anti-inflammatory treatment in children with bronchial asthma.

(Arch Dis Child 1995; 73: 413-417)
\end{abstract}

Keywords: asthma, eosinophils, eosinophil cationic protein, infection.

Divisions of Allergy and Pulmonology, University Children's Hospital, Vienna, Austria

D Y Koller

Y Herouy

M Götz

R Urbanek

I Eichler

\section{Department of} Paediatrics, Wilhelminen Hospital Vienna, Austria E Hagel

Correspondence and reprint requests to: Dr Dieter Koller, University Children's

University Children's 18-20, 1090 Vienna, Austria.

Accepted 25 May 1995

Asthma is a chronic inflammatory disease, which is characterised by symptoms of airway obstruction such as cough, wheezing, and breathlessness. Bronchial inflammation in asthma can be assessed directly by pathohistological observations and indirectly by examining cells and mediators present in peripheral blood. ${ }^{12}$ In adults the implication of eosinophils in bronchial asthma is well accepted. ${ }^{3}$ A correlation between activated eosinophils and pulmonary function or non-specific bronchial hyperreactivity was observed. ${ }^{4}$ Moreover, activated eosinophils release granule derived proteins, the most accepted of which is eosinophil cationic protein (ECP) for estimation of eosinophil activation. ${ }^{56}$

In vitro studies have shown the deleterious effect to bronchial mucosa of eosinophil derived cytotoxic proteins ${ }^{57}$ and assessment of serum ECP has been suggested for monitoring disease activity and bronchial inflammation ${ }^{8}$ in adult bronchial asthma. In childhood asthma, however, problems in diagnosing or monitoring disease activity may occur because of nonspecific symptoms as well as the inability to obtain reliable pulmonary function and provocation tests in children less than 5 years of age. Thus, monitoring by the assessment of mediators, reflecting pulmonary inflammation, ${ }^{6}$ could support an optimal management of childhood asthma.

To evaluate the clinical value of activated eosinophils in children with bronchial asthma, serum ECP and blood eosinophil counts were determined. Sensitisation to inhalant allergens as well as infections of both the upper and the lower respiratory tract are known to cause exacerbations in asthmatic children. ${ }^{9}$ To differentiate between various factors assumed to influence eosinophil activities, the patients therefore were subdivided into groups due to treatment modalities, to atopy and infection. In addition, healthy non-atopic children and patients with cystic fibrosis and lower respiratory tract infections (LRTI) were used as controls.

\section{Subjects and methods}

PATIENTS AND CONTROLS

A total of 175 children ( 78 girls and 97 boys) with bronchial asthma (diagnosis was based on episodic cough, wheeze, and breathlessness that was responsive to $\beta_{2}$ agonists, and after other conditions have been excluded) were enrolled for this study (mean (SD) age 9.8 (3.8) years; 52 of the patients were less than 6 years of age)

At the time of examination the children were divided into different treatment groups: (1) salbutamol, 11 with fenoterol); (2) 37 on inhaled steroids (29 with budesonide, eight with beclomethasone); (3) 47 on inhaled steroids and $\beta_{2}$ agonists; (4) 27 on inhaled sodium cromoglycate; and (5) 20 children with bronchial asthma who were newly diagnosed and thus without antiasthmatic medication. In 14 of these patients treatment was initiated with budesonide ( $600 \mu \mathrm{g}$ daily) and salbutamol (300 $\mu \mathrm{g}$ daily) for two weeks, and thereafter with budesonide alone. Every two weeks follow up examinations, including pulmonary function and blood sampling, were 
performed for a period of four weeks. The remaining six patients were first treated with oral antibiotics - due to LRTI - and an inhaled $\beta_{2}$ agonist (salbutamol $300 \mu \mathrm{g}$ daily) for 10 days and thereafter with inhaled budesonide (600 $\mu \mathrm{g}$ daily).

The controls comprised: (1) 23 nonasthmatic children with LRTI (14 girls and nine boys; age $8.6(2.5)$ years) before initiating antibiotic treatment. (2) Forty five patients with cystic fibrosis ( 22 girls and 23 boys; age $10.8(6.5)$ years); 20 of these patients were colonised with Pseudomonas aeruginosa and/or Staphylococcus aureus as proved by sputum cultures. Clinical condition was assessed by the method of Shwachman-Kulczycki ${ }^{10}$ without reviewing the $x$ ray resulting in a score between $0-75$. The median score in our patients investigated was 55 (range 24-73). Acute pulmonary exacerbation in cystic fibrosis was defined as marked increase of $\mathrm{C}$ reactive protein (median concentration $129 \mathrm{mg} / \mathrm{l}$ ), by weight loss, anorexia, increased cough, increased sputum production, fever with and without new lung infiltrates, deterioration of oxygen saturation and lung function. None of these patients received systemic or inhaled steroids within the month of blood drawing. (3) Eighty seven healthy children ( 51 girls and 36 boys; age $10 \cdot 2$ $(4.5)$ years) with no history of atopy or asthma and normal total serum IgE concentrations, who were free of infection for at least two weeks before the drawing of blood were recruited as normal references.

Parental agreement to blood sampling was obtained in all cases and blood was obtained at routine sampling for clinical evaluation.

DEFINITION OF ATOPIC STATUS

Patients were defined as being atopic by having increased total serum IgE antibody concentrations and by the presence of specific IgE antibodies against at least two or more inhalant allergens tested (Dermatophagoides pteronyssinus and $D$ farinae, cat, dog, alternaria, cladosporium, aspergillus, birch, alder, hazel, and grass pollens).

\section{DEFINITION OF INFECTION IN CHILDREN WITH} BRONCHIAL ASTHMA

Infection of the upper or lower respiratory tract was diagnosed clinically, by leucocytosis, radiographic evidence of pulmonary infiltrates and - if possible - by sputum cultures and evidence of viral antigens in nasal fluids.

\section{CLINICAL EVALUATION AND PULMONARY} FUNCTION

Physical examination and a history of wheeze, cough (nocturnal), and dyspnoea within the last two weeks before blood sampling allowed to divide the patients into symptomatic and asymptomatic children with bronchial asthma.

Pulmonary function tests were performed as compliance of the patients and/or parents allowed - in 52 children with bronchial asthma and 38 patients with cystic fibrosis as follows.
Forced vital capacity (FVC), forced expiratory volume in the first second $\left(\mathrm{FEV}_{1}\right)$ and maximum expiratory flow at 50\% (MEF50) and at $25 \%$ (MEF25) of vital capacity were recorded in the form of a maximum flow volume curve (Masterlab, Jaeger, Germany) according to the American Thoracic Society standard. ${ }^{11}$ The best of three efforts was used for calculations. Results were presented as percent predicted based on accepted reference standards. ${ }^{12}$

\section{BLOOD SAMPLES}

Blood eosinophil counts were determined by automated counting (Sysmex NE-5500; Müller GesmbH, Austria) with a coefficient of variation about $7 \cdot 0 \%$. Serum was used for the determination of ECP. Assessments were done by using a sensitive and specific double antibody radioimmunoassay (Pharmacia Diagnostics, Sweden) in which ECP in the samples competes with a fixed amount of ${ }^{125} \mathrm{I}$ labelled ECP for the binding sites of specific antibodies. ${ }^{1314}$ The interassay coefficient of variation for the assay was less than $10 \%$.

Total serum IgE and specific IgE antibodies were measured by using enzyme immunoassays (Kallestad Diagnostics, USA).

\section{STATISTICAL ANALYSIS}

Results are expressed as medians (quartile 1-quartile 3) unless mentioned otherwise. Correlation coefficients were obtained using the Kendall Tau B test. Non-parametric statistical tests were used in comparative analysis. The Kruskal-Wallis analysis was applied first to the data in all groups. When this was significant, each pairing was examined by means of the Mann-Whitney U test. Changes related to treatment were tested for significance using Wilcoxon signed ranks test for paired samples. Probabilities of less than $5 \%$ were taken as statistically significant.

\section{Results}

CHARACTERISTICS OF PATIENTS

At the time of examination, 90 asthmatic children with bronchial asthma were asymptomatic whereas 85 patients had symptoms of airway obstruction within the last two weeks before examination; 105 children presented with specific sensitisation against two or more of tested allergens. Total serum IgE concentrations were significantly increased in the atopic group (median: $457 \mathrm{kU} / \mathrm{l}$ ) compared with the non-atopic asthmatics (median:

Table 1 Eosinophil counts as well as serum ECP concentrations in children with bronchial asthma, cystic fibrosis, and LRTI compared with healthy non-atopic subjects

\begin{tabular}{lll}
\hline & Eosinophils (cells/ $\mu l)$ & ECP $(\mu g /)$ \\
\hline Bronchial asthma & $443(290-601)$ & $34 \cdot 3(22 \cdot 5-55 \cdot 2)$ \\
Cystic fibrosis & $235(105-350)$ & $65 \cdot 7(39 \cdot 8-82 \cdot 5)$ \\
LRTI & $205(125-230)$ & $12 \cdot 3(8 \cdot 7-16 \cdot 3)$ \\
Controls & $209(118-328)$ & $9 \cdot 8(7 \cdot 3-13 \cdot 5)$ \\
\hline
\end{tabular}

Results are presented as median (quartile 1-quartile 3); $p$ values in text (see results section). 
Table 2 Serum ECP and eosinophil counts in symptomatic and asymptomatic children with bronchial asthma subdivided into treatment groups

\begin{tabular}{|c|c|c|c|c|c|c|}
\hline & \multicolumn{3}{|l|}{$E C P(\mu g /)$} & \multicolumn{3}{|l|}{ Eosinophils/ $\mu l$} \\
\hline & Symptomatic & Asymptomatic & p Value & Symptomatic & Asymptomatic & p Value \\
\hline Untreated & $\begin{array}{l}43 \cdot 4(36 \cdot 4-68 \cdot 8) \\
{[n=20]}\end{array}$ & & & $388(278-545)$ & & \\
\hline$\beta_{2}$ Agonists & $\begin{array}{l}39 \cdot 9(22 \cdot 1-59 \cdot 5) \\
{[n=18]}\end{array}$ & $\begin{array}{l}13 \cdot 4(11 \cdot 2-31 \cdot 8) \\
{[n=26]}\end{array}$ & $\mathrm{p}<0.005$ & $404(254-509)$ & $398(110-400)$ & NS \\
\hline Steroids & $\begin{array}{l}48 \cdot 5(20 \cdot 5-70 \cdot 9) \\
{[n=17]}\end{array}$ & $\begin{array}{l}14 \cdot 3(10 \cdot 0-23 \cdot 5) \\
{[n=20]}\end{array}$ & $\mathrm{p}<0.005$ & $347(210-580)$ & $311(188-411)$ & NS \\
\hline Steroids and $\beta_{2}$ agonists & $\begin{array}{l}33 \cdot 0(17 \cdot 0-54 \cdot 3) \\
{[n=20]}\end{array}$ & $\begin{array}{l}15 \cdot 0(12 \cdot 0-24 \cdot 4) \\
{[n=27]}\end{array}$ & $\mathrm{p}<0.001$ & $335(289-481)$ & $360(320-450)$ & NS \\
\hline Sodium cromoglycate & $\begin{array}{l}41 \cdot 4(24 \cdot 6-76 \cdot 4) \\
{[n=10]}\end{array}$ & $\begin{array}{l}14 \cdot 7(9 \cdot 8-23 \cdot 9) \\
{[n=17]}\end{array}$ & $\mathrm{p}<0.001$ & $387(254-467)$ & $365(298-485)$ & NS \\
\hline
\end{tabular}

Results are presented as median (quartile 1-quartile 3); $\mathrm{p}$ values=statistical differences between symptomatic and asymptomatic children with bronchial asthma. NS = not significant.

$17 \mathrm{kU} / \mathrm{l} ; \mathrm{p}<0.0001)$. Infection of the lower or upper respiratory tract was present in 77 children with bronchial asthma at the time of examination.

Assessment of pulmonary function in $\mathbf{5 2}$ of the asthmatics showed for symptomatic children $(n=31)$ a median (range) $\mathrm{FEV}_{1}$ value of $78.4 \%$ predicted $(47 \cdot 9-89 \cdot 0 \%$ ), MEF50 value of $62.9 \%$ predicted $(25 \cdot 7-75 \cdot 0 \%)$, and MEF25 value of $58 \cdot 1 \%$ predicted (20.6-72.9\%). Asymptomatic asthmatics $\left(\mathrm{n}=21\right.$ ) demonstrated a median (range) $\mathrm{FEV}_{1}$ value of $95 \cdot 6 \%$ predicted (88.6-120\%), MEF50 value of $90 \cdot 1 \%$ predicted (79.8-124.5\%), and MEF25 value of $85 \cdot 2 \%$ predicted (73.9-112.4\%).

In patients with cystic fibrosis $(n=38)$ median (range) $\mathrm{FEV}_{1}$ was $74.2 \%$ predicted (22.8-135.8\%), a median MEF50 50.0\% predicted (5.7-92.4\%), and MEF25 30.8\% predicted (3.9-91.5\%). In addition, atopy was observed in 24 children with cystic fibrosis as proved by specific sensitisation against inhalant allergens and increased total serum IgE concentrations (median $480 \mathrm{kU} / \mathrm{l}$ ) compared with 21 non-atopic patients with cystic fibrosis (median $26 \mathrm{kU} / \mathrm{l} ; \mathrm{p}<0.0001$ ).

\section{BRONCHIAL ASTHMA, CYSTIC FIBROSIS, AND} LRTI

Eosinophil counts in peripheral blood were significantly increased in children with bronchial asthma compared with control subjects $(\mathrm{p}<0.005)$, to patients with cystic fibrosis $(p<0.005)$, and to children with LRTI $(\mathrm{p}<0.005$; table 1). Eosinophil numbers in asthmatic children were weakly correlated with serum concentrations of ECP $\quad(r=0.316$; $\mathrm{p}<0.0001)$. In asthmatic children, serum ECP was raised in comparison with LRTI $(p<0.001)$ and with healthy controls $(p<0.0001)$, but were not different to ECP concentrations in samples obtained from patients with cystic fibrosis (table 1).

Subdivision into symptomatic and asymptomatic asthmatic children demonstrated significant differences for serum ECP concentrations (table 2) whereas eosinophil counts were not different (table 2). In addition, symptomatic patients with bronchial asthma had serum concentrations of ECP within the same pathological range, irrespective if treated with steroids, $\beta_{2}$ agonists, or sodium cromoglycate (table 2). Serum ECP and eosinophil counts did not differ significantly between the younger (less than 6 years) and the older (more than 6 years) patients.

ECP concentrations in sera of patients with bronchial asthma were not correlated with variables of pulmonary function. In patients with cystic fibrosis, however, a relationship with pulmonary function as measured by $\mathrm{FEV}_{1}$ predicted $(r=-0.634 ; \mathrm{p}<0.001)$ and the Shwachman-Kulczycki score $\quad(r=-0.678$; $\mathrm{p}<0.001$ ) was given.

\section{EOSINOPHIL COUNTS AND SERUM ECP IN}

ATOPIC BRONCHIAL ASTHMA

In children with atopic bronchial asthma both serum ECP concentrations as well as eosinophil counts were increased (table 3 ) compared with asthmatic patients without atopy. Atopic

Table 3 Atopy: influence on serum ECP and eosinophil counts in children with bronchial asthma on different medication and in cystic fibrosis

\begin{tabular}{|c|c|c|c|c|c|c|}
\hline & \multicolumn{3}{|l|}{$E C P(\mu g /)$} & \multicolumn{3}{|c|}{ Eosinophils (cells/ $\mu)$} \\
\hline & Non-atopic & Atopic & p Value & Non-atopic & Atopic & p Value \\
\hline \multicolumn{7}{|l|}{ Bronchial asthma } \\
\hline Untreated & $\begin{array}{l}36 \cdot 8(15 \cdot 7-48 \cdot 5) \\
{[n=9]}\end{array}$ & $\begin{array}{l}58 \cdot 4(42 \cdot 1-80 \cdot 7) \\
{[n=11]}\end{array}$ & $\mathrm{p}<0.05$ & $367(250-478)$ & $485(390-660)$ & $p<0.05$ \\
\hline$\beta_{2}$ Agonists & $\begin{array}{l}12 \cdot 7(8 \cdot 1-21 \cdot 9) \\
{[n=12]}\end{array}$ & $\begin{array}{l}32 \cdot 4(13 \cdot 8-43 \cdot 0) \\
{[n=32]}\end{array}$ & $\mathrm{p}<0.01$ & $222(100-310)$ & $386(230-484)$ & $\mathrm{p}<0.05$ \\
\hline Steroids & $\begin{array}{l}20 \cdot 0(8 \cdot 0-28 \cdot 0) \\
{[n=15]}\end{array}$ & $\begin{array}{l}23 \cdot 5(12 \cdot 0-51 \cdot 6) \\
{[n=22]}\end{array}$ & NS & $320(240-423)$ & $480(300-640)$ & $\mathrm{p}<0.05$ \\
\hline Steroids and $\beta_{2}$ agonists & $\begin{array}{l}19 \cdot 5(12 \cdot 0-39 \cdot 0) \\
{[n=22]}\end{array}$ & $\begin{array}{l}19 \cdot 0(12 \cdot 0-36 \cdot 0) \\
{[n=25]}\end{array}$ & NS & $343(312-450)$ & $453(320-612)$ & p $<0.05$ \\
\hline Sodium cromoglycate & $\begin{array}{l}18 \cdot 8(9 \cdot 8-29 \cdot 4) \\
{[n=12]}\end{array}$ & $\begin{array}{l}29 \cdot 9(10 \cdot 8-44 \cdot 7) \\
{[n=15]}\end{array}$ & $p<0.05$ & $334(298-417)$ & $465(312-608)$ & $\mathrm{p}<0.05$ \\
\hline Cystic fibrosis & $\begin{array}{l}61 \cdot 3(9 \cdot 8-71 \cdot 4) \\
{[n=26]}\end{array}$ & $\begin{array}{l}55 \cdot 0(13 \cdot 2-65 \cdot 8) \\
{[n=19]}\end{array}$ & NS & $180(120-220)$ & $160(90-280)$ & NS \\
\hline
\end{tabular}

Results are presented as median (quartile 1-quartile 3); $p$ values indicate significant differences between atopics and non-atopics. NS = not significant. 
Table 4 Infection: influence on serum ECP in children with bronchial asthma (subdivided into different treatment groups), cystic fibrosis, and with LRTI

\begin{tabular}{|c|c|c|c|}
\hline & \multicolumn{3}{|l|}{$E C P(\mu g /)$} \\
\hline & Infection & No infection & p Value \\
\hline $\begin{array}{l}\text { Bronchial asthma } \\
\text { Untreated } \\
\beta_{2} \text { Agonists } \\
\text { Steroids } \\
\text { Steroids and } \beta_{2} \text { agonists } \\
\text { Sodium cromoglycate } \\
\text { Cystic fibrosis } \\
\text { LRTI }\end{array}$ & $\begin{array}{l}68 \cdot 8(50 \cdot 0-85 \cdot 5) \\
{[n=6]} \\
35 \cdot 3(32 \cdot 5-58 \cdot 3) \\
{[n=23]} \\
63 \cdot 2(26 \cdot 3-76 \cdot 6) \\
{[n=17]} \\
54 \cdot 0(39 \cdot 0-114 \cdot 0) \\
{[n=18]} \\
57 \cdot 4(38 \cdot 2-76 \cdot 4) \\
{[n=13]} \\
30 \cdot 4(13 \cdot 2-57 \cdot 3) \\
{[n=17]} \\
12 \cdot 3(8 \cdot 7-16 \cdot 3) \\
{[n=23]}\end{array}$ & $\begin{array}{l}42 \cdot 2(36 \cdot 3-48 \cdot 5) \\
{[n=14]} \\
20 \cdot 1(12 \cdot 1-37 \cdot 7) \\
{[n=21]} \\
15 \cdot 4(11 \cdot 8-26 \cdot 7) \\
{[n=20]} \\
17 \cdot 0(12 \cdot 0-32 \cdot 0) \\
{[n=29]} \\
18 \cdot 9(8 \cdot 9-29 \cdot 8) \\
{[n=14]} \\
48 \cdot 8(9 \cdot 8-65 \cdot 8) \\
{[n=28]}\end{array}$ & $\begin{array}{l}\mathrm{p}<0.05 \\
\mathrm{p}<0.05 \\
\mathrm{p}<0.005 \\
\mathrm{p}<0.001 \\
\mathrm{p}<0.005 \\
\mathrm{NS}\end{array}$ \\
\hline
\end{tabular}

Results are expressed as median (quartile 1-quartile 3 ); $p$ values indicate significant differences between infected and non-infected patients. NS = not significant.

patients with bronchial asthma treated with $\beta_{2}$ agonists and sodium cromoglycate had significantly higher concentrations of ECP than nonatopic subjects treated with these agents whereas atopic patients treated with inhaled steroids had similar concentrations of ECP to non-atopic children treated with inhaled steroids (table 3 ). Total eosinophil counts, however, were unaffected by inhaled steroids, thus no differences for eosinophil counts in each treatment group between atopic and non-atopic asthmatic children could be observed (table 3 ).

\section{EOSINOPHIL COUNTS AND SERUM ECP IN INFECTION}

Infection caused an increase of ECP in childhood asthma but not in patients with cystic fibrosis and with LRTI (table 4). Eosinophil counts, however, were not altered (median 378 cells $/ \mu \mathrm{l} v 328 \mathrm{cells} / \mu \mathrm{l})$.

\section{EFFECT OF INHALED BUDESONIDE ON SERUM ECP}

Treatment with budesonide ( $600 \mu \mathrm{g} /$ daily) for four weeks and salbutamol (300 $\mu \mathrm{g} /$ daily) for two weeks in 14 children with newly diagnosed

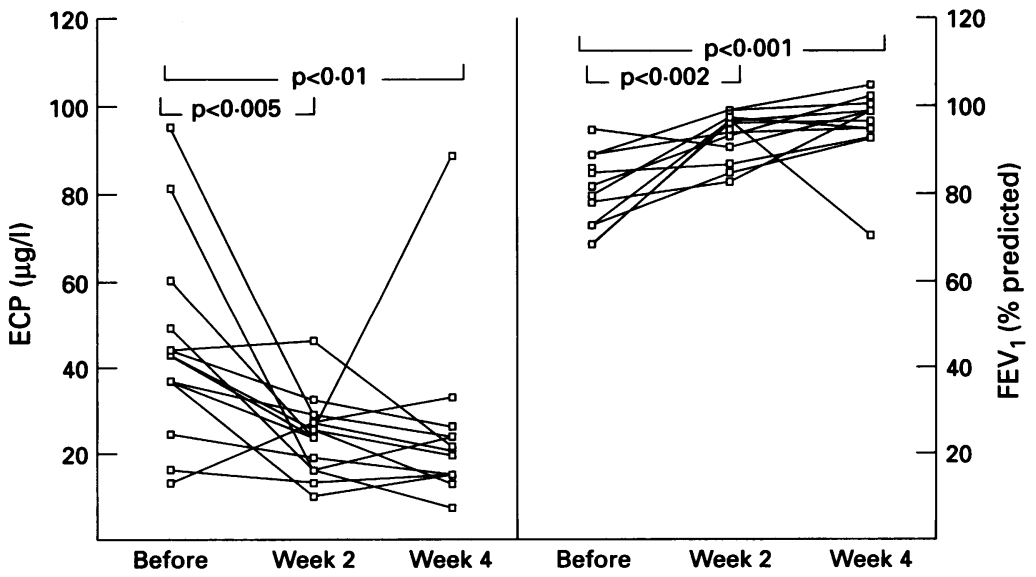

Figure 1 The change in serum concentrations of ECP and FEV in 14 newly diagnosed asthmatic children. Examinations were performed before starting treatment, after two weeks of treatment with budesonide and salbutamol and after the following two weeks of treatment with budesonide alone. Median serum ECP concentration before treatment: $42 \cdot 2 \mu \mathrm{g} /$; after 2 weeks: $23.9 \mu \mathrm{g} /$; after 4 weeks: $19.0 \mu \mathrm{g} /$. Median $F E V_{1} \%$ predicted before treatment: 82.9\%; after 2 weeks: $94 \cdot 1 \%$; after 4 weeks: $97 \cdot 4 \%$. No significant changes of eosinophil counts were observed. bronchial asthma resulted in a significant decrease of serum ECP and improvement of pulmonary function (fig 1). Eosinophil counts (median eosinophil count before treatment: 388 cells/ $\mu$ l; after two weeks treatment with budesonide and salbutamol: $400 \mathrm{cells} / \mu \mathrm{l}$; after additional two weeks with budesonide alone: 364 cells $/ \mu \mathrm{l}$ ) did not change significantly.

In children $(n=6)$ with bronchial asthma presenting with LRTI oral antibiotic and inhaled $\beta_{2}$ agonist treatment resulted in no significant change of ECP concentrations within 10 days (fig 2). Only inhalation of budesonide $(600 \mu \mathrm{g} / \mathrm{l})$ caused a significant reduction of serum ECP concentrations $(p<0.03)$ in these patients (fig 2).

\section{Discussion}

Inflammation is being increasingly recognised as a major factor in childhood asthma. One of the predominant inflammatory cells in the asthmatic lung is the eosinophil granulocyte, which has been suggested to contribute to bronchial hyperreactivity and tissue injury. ${ }^{13}$ The activity of eosinophils could be determined by the measurement of eosinophil granule proteins, such as ECP. In addition, assessment of serum ECP has been assumed to reflect pulmonary inflammation in bronchial asthma. 568

We have found increased blood eosinophil counts and more significantly increased serum concentrations of ECP in children with bronchial asthma compared with a group of age and sex matched normal healthy control subjects. ECP concentrations were not different between children less or more than 6 years of age, as previously reported. ${ }^{15}$ The median serum ECP concentrations were raised, however, with many patients having normal values. This could be explained partly by the fact that inhaled steroids reduce the concentrations of ECP due to the direct inhibitory effect on eosinophil activation. ${ }^{15}$ However, many children on $\beta_{2}$ agonists alone, also demonstrated low ECP despite published data, showing no in vitro effect of $\beta_{2}$ agonists on eosinophil activation. ${ }^{16}$ By dividing children with bronchial asthma into symptomatic and into asymptomatic patients we were able to demonstrate that symptomatic children had higher ECP concentrations than asymptomatic asthmatics, independent of treatment modalities (that is inhaled steroids, $\beta_{2}$ agonists, combination of both, or sodium cromoglycate). These results suggest that determination of serum ECP may be useful for assessing asthma severity. In addition, measurement of raised serum ECP concentrations may reflect the ongoing inflammation in the asthmatic lung and may therefore be used to predict the need for intensified anti-inflammatory treatment modalities. Similar findings were reported only recently. ${ }^{15}$ To emphasise this hypothesis, we were able to demonstrate the effectiveness of inhaled steroids in suppressing eosinophil activity in a four week prospective trial. Improvement of pulmonary function was strongly associated with a fall of serum ECP, in all subjects investigated, suggesting that 


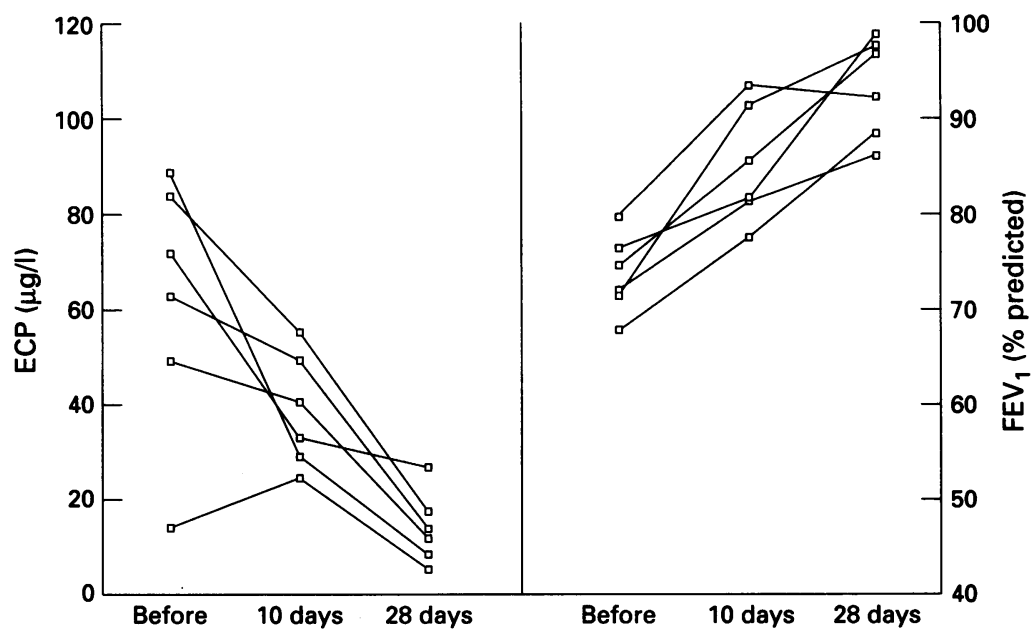

Figure 2 The change in serum concentrations of ECP and of FEV in six newly diagnosed asthmatic children with infection of the lower respiratory tract infection. Examinations were done before starting treatment, after 10 days of treatment by oral antibiotics and inhaled salbutamol, and after 18 days of treatment by budesonide and salbutamol. Median serum ECP concentrations before treatment: $68.8 \mu \mathrm{g} /$; after 10 days: $38.2 \mu g /(p=N S$ compared values on day 0$)$; after 28 days: $13.5 \mu g h(p<0.03$ compared to values on day 0$)$. Median $F E V_{1} \%$ predicted before treatment: $73.9 \%$; after 10 days: $85.4 \%$ ( $p<0.05$ compared with values on day 0$)$; after 28 days: $96.0 \%(p<0.03$ compared with values on day 0 ). mechanisms of eosinophil activation than in patients with bronchial asthma. ${ }^{14}$ Another explanation might be that in cases with normal or moderately high eosinophil numbers, the reduced availability may be compensated for by the increased activity of cells, which is enough to achieve sufficient concentrations of the inducers of the inflammatory process.

In conclusion, our findings demonstrated increased serum ECP concentrations in children with bronchial asthma. By these results, it has become likely that the eosinophil plays a central part in the asthmatic inflammation in children, as it does in adults. In addition, our data suggest that the determination of serum ECP may be used for monitoring the disease activity. As both atopy and infection caused increased ECP concentrations - that is enhanced eosinophil activation - we hypothesise that both may act as 'boosting factors' for inflammatory processes in bronchial asthma. Finally, our results suggest that serum ECP measurements may be useful to predict the need for intensified anti-inflammatory treatment.

It may be that assessment of mediators will allow further investigation of important and until now unanswered questions in childhood asthma, namely: When is the onset of eosinophilic inflammation in the asthmatic child? and What is first: bronchial hyperreactivity or inflammation?

1 Gleich GJ. The eosinophil and bronchial asthma: current understanding. F Allergy Clin Immunol 1990; 85: 422-36.

2 Ayars GH, Altman LC, Gleich GJ, Loegering DA, Baker CB. Eosinophil- and eosinophil granule-mediated pneumocyte injury. F Allergy Clin Immunol 1985; 76: 595-604.

3 Bousquet J, Chanez P, Lacoste JY, et al. Eosinophilic inflammation in asthma. N Engl $\mathcal{f}$ Med 1990; 323: 1033-9.

4 Ferguson AC, Wong FWM. Bronchial hyperresponsiveness in asthmatic children. Correlation with macrophages and eosinophils in broncholavage fluid. Chest 1989; 96: 988-91.

5 Spry CFJ. Eosinophils: a comprehensive review, and a guide to the scientific and medical literature. Oxford: Oxford University Press, 1988.

6 Venge P, Dahl D, Fredens K, Hällgren R, Peterson C. Eosinophil cationic proteins (ECP and EPX) in health and disease. In: Yoshida T, Torisu M, eds. Immunobiology of the eosinophil. New York: Elsevier, 1983: 163-79.

7 Flavahan NA, Shifman NR, Gleich GJ, Vanhutte PM. Human eosinophil major basic protein causes hyperreactivity of respiratory smooth muscle: role of the epithelium. Am Rev Respir Dis 1988; 138: 685-8.

8 Hallgren $R$, Venge $P$. The eosinophil in inflammation. In: Matsson P, Ahlstedt S, Venge $P$, Thorell J, eds. Clinical impact of monitoring of allergic inflammation. London: impact of monitoring of allergic

9 Warner JO, Götz M, Landau LI, et al. Management of asthma. A consensus statement. Arch Dis Child 1989; 64: asthma. A

10 Shwachman H, Kulzcycki L. Long-term study of 105 patients with cystic fibrosis. Am $\mathcal{F}$ Dis Child 1958; 96: 6-15. 11 American Thoracic Society. Standardization of spirometry - 1987 update. Am Rev Respir Dis 1987; 2: 1285-98.

12 Zapletal A, Samanek M, Paul T. Lung-function in children and adolescents. Methods, reference values. Progress in Respiratory Research 1987; 22: 113-218.

13 Venge P, Roxin LE, Olsson I. Radioimmunoassay of human eosinophil cationic protein. Br f Haematol 1977; 37: 331-6.

14 Koller DY, Urbanek R, Götz M. Increased degranulation of eosinophil and neutrophil granulocytes in cystic fibrosis. Am $\mathcal{F}$ Respir Crit Care Med 1995 (in press).

15 Zimmerman B. Enander I, Zimmerman R, Ahlstedt S. Asthma in children less than 5 years of age: eosinophils and serum levels of the eosinophil proteins ECP and EPX in relation to atopy and symptoms. Clin Exp Allergy 1994; 24: $149-55$.

16 Yukawa T, Chanez P, Dent G, et al. Bronchodilator agents do not inhibit oxygen free radical release from guinea pig (abstract).

17 Horn BR, Robin ED, Theodore J, Van Kessel A. Total esinophil counts in the management of bronchial eosinophil counts in the management
asthma. $N$ Engl $\mathcal{F}$ Med $1975 ; 292: 1152-5$.

18 Frick WE, Sedgwick JB, Busse WW. The appearance of hypodense eosinophils in antigen-dependent late phase asthma. Am Rev Respir Dis 1989; 139: 1401-6.

19 Koller DY, Götz M, Eichler I, Urbanek R. Eosinophilic activation in cystic fibrosis. Thorax 1994; 49: 496-9. in patients with cystic fibrosis in the presence of increased serum ECP thus suggest different 